\title{
Numerical Studies on Minimum Ignition Energies in Methane/Air and Isooctane/Air Mixtures
}

\author{
Chunwei $\mathrm{Wu}^{a}$, Robert Schieß1 ${ }^{a} \&$ Ulrich Maas $^{a}$ \\ ${ }^{a}$ Institute of Technical Thermodynamics, Karlsruhe Institute of Technology, Karlsruhe, Germany \\ E-mail: chunwei.wu@kit.edu
}

\begin{abstract}
In this study, the dependence of minimum ignition energies (MIE) on ignition geometry, ignition source radius and mixture composition is investigated numerically for methane/air and isooctane/air mixtures. Methane and isooctane are both important hydrocarbon fuels, but differ strongly with respect to their Lewis numbers. Lean isooctane air mixtures have particularly large Lewis numbers. The results show that within the flammability limits, the MIE for both mixtures stays almost constant, and increases rapidly at the limits. The MIEs for both fuels are also similar within the flammability limits. Furthermore, the MIEs of isooctane/air mixtures with a small spherical ignition source increase rapidly for lean mixtures. Here the Lewis number is above unity, and thus, the flame may quench because of flame curvature effects. The observations show a distinct difference between ignition and flame propagation for iso-octane. The minimum energy required for initiating a successful flame propagation can be considerably higher than that required for initiating an ignition in the ignition volume. For iso-octane with a small spherical ignition source, this effect was observed at all equivalence ratios. For iso-octane with cylindrical ignition sources, the phenomenon appeared at lower equivalence ratios only, where the mixture's Lewis number is large. For methane fuel, the effect was negligible. The results highlight the significance of molecular transport properties on the decision whether or not an ignitable mixture can evolve into a propagating flame.
\end{abstract}

Keywords: Ignition energy, spark ignition, detailed chemistry

\section{Introduction}

Flame initiation is one of the essential problems in combustion processes. It is either desired, e.g., in gasoline engines, or one seeks to prevent it, like in explosion-critical environments. In both cases, understanding details of the flame initiation and early flame propagation can help for improving processes. In IC engines, this understanding allows for improved designs with better fuel efficiency and lower emission. Thus, the investigation of flame initiation is especially important for combustion engines.

It is well known that for a successful induced ignition, a minimum ignition energy (MIE) is needed to achieve high temperatures of the fuel-air mixture in the ignition volume to allow fast chemical reactions to commence. This leads to the formation of a flame kernel, which then might give rise to further propagation of a self-sustained flame. In the past, the dependence of MIE on the pressure, initial temperature, mixture stoichiometry and ignition source volume for different fuels has been investigated (see e.g. Maas et al., 1988, Frendi et al., 1990, Lewis et al., 1987). There are two possibilities after a certain amount of external energy is deposited: the spherical flame propagates outwardly and finally becomes a planar flame or the flame quenches.

The flame initiation and early propagation of the simpler fuels like hydrogen or methane is well studied. For isooctane, an important component and model fuel for gasoline, less studies are available. Beside its practical significance, the case of induced ignition in iso-octane/air mixtures is also 
interesting from a more fundamental viewpoint, because at least two physical or chemical aspects of this fuel are more complicated than for $\mathrm{CH}_{4}$. The Lewis number (see e.g. Mills et al., 1993) of isooctane/air mixtures is very different from that of methane/air mixtures: while the Lewis number for methane/air mixtures is overall close to 1 at atmospheric pressure and room temperature (Clarke, 2002), the Lewis number of isooctane/air mixtures varies from under unity at rich condition to 3 for lean mixtures (Takashi et al., 2006, Abdel-Gayed et al., 1985). Also, iso-octane as a higher hydrocarbon features a more complicated chemistry during its oxidation compared methane; also in this behavior, iso-octane is closer to most practical gasoline-type fuels than methane.

This work aims to investigate the MIEs for methane and isooctane with different fuel compositions (throughout the flammable range), different ignition source geometries (spherical and cylindrical) and different ignition source sizes $(0.5 \mathrm{~mm}$ to $3 \mathrm{~mm})$ at 1 bar and $298 \mathrm{~K}$, in order to find out the ignition properties of the two fuels, and to better understand how the interplay of chemical reaction and transport effects (in particular, species diffusion and heat conduction) affect the ignition process. It uses numerical simulations, involving a detailed treatment of chemical reactions and molecular transport effects, for this.

\section{Numerical Method}

Model simulations of flame initiation were performed using the in-house code INSFLA (Maas et al., 1988). This code computes the temporal evolution of combustion processes in one-dimensional geometries, considering detailed chemistry and detailed molecular transport.

The simulations use a domain which depends on one spatial variable $r$; this can describe cylindrically symmetric domains with infinite extent in axial direction and spherically symmetric domains. Simulations are initialized with a compositionally and thermally homogeneous fuel/air mixture at some predefined initial conditions. The combustion processes are calculated based on the assumption of constant pressure ( 1 bar), and the initial temperature was set to a homogeneous profile with $298 \mathrm{~K}$. The air used in this study has a composition of $21 \% \mathrm{O}_{2}$ and $79 \% \mathrm{~N}_{2}$ by mole. The investigated fuel compositions are varied within an interval that includes the flammability limits (from $\Phi=0.46$ to $\Phi$ $=1.86$ for methane/air mixtures and from $\Phi=0.77$ to $\Phi=4.57$ for isooctane/air mixtures).

Starting from $t=0$, an energy source term is applied for a duration (ignition duration) of $10^{-4} \mathrm{~s}$ in a region (whose size is defined by the ignition radius $r_{s}$ ) at the inner domain boundary $(r=0)$. In the following, this region will be referred to as ignition kernel. We considered both spherical and cylindrical ignition kernels. For each ignition geometry, several ignition radii (ranging from $r=0.5$ $\mathrm{mm}$ to $r=3 \mathrm{~mm}$ ) were investigated.

In order to compare the MIE between different ignition geometries and ignition radii, the minimum ignition energy density $q$ is used, defined as

$$
q=\frac{E}{V_{S}}
$$

Here $E$ is the ignition energy and $V_{S}$ is the ignition kernel volume.

For spherical geometry, $\mathrm{E}$ is the total energy deposited at the center of the gas mixture, $\mathrm{E}$ is in $\mathrm{J}$.

The energy density is

$$
q=\frac{E_{s p h}}{\frac{4}{3} \pi r_{s}{ }^{3}} .
$$

For cylindrical geometry (infinite cylinder, Maas et al. 1988), E is the deposited energy per length of the infinite cylinder, and has a unit of $\mathrm{J} / \mathrm{m}$. So we only need to divide $\mathrm{E}$ by the circle area in order to calculate the energy density

$$
q=\frac{E_{c y l}}{\pi r_{s}^{2}}
$$


The computational domain size for $r_{s} \leq 1 \mathrm{~mm}$ was set to $0.01 \mathrm{~m}$, while for $r_{s}>1 \mathrm{~mm}$, it was set to $0.05 \mathrm{~m}$. Thus, there was sufficient space to make sure the outer boundary of the domain did not affect the ignition process and early phase of flame propagation.

Premixed methane/air mixtures and isooctane/air mixtures were used as fuels in this present study. We used the GRI 3.0 mechanism with 53 species and 325 reactions to describe the detailed chemical kinetics of methane (Smith et al., 2004). A semi-detailed chemical kinetics model for Toluene Reference Fuels (TRF) with 137 species and 633 reactions is used, which also contains chemistry for iso-octane (Andrae et al., 2008).

Running the code delivers spatiotemporal profiles of temperature and species. Temperature profiles are analysed to decide between flame propagation and flame extinction. For example, fig. 1 shows the temperature profiles for the case of a successful ignition (diagram (a)), and also for an ignition failure (diagram (b)). As can be seen, in a successful ignition, the temperature in the center of the mixture rises and a flame kernel is formed; after some time, a self-sustaining flame starts to propagate outwards. On the other hand, in an ignition failure, the heat is conducted to the surroundings, and the the temperature at the center finally decreases back to $298 \mathrm{~K}$.

Isooctane, $\Phi=1.6$, spherical geometry, $r_{\mathrm{s}}=2 \mathrm{~mm}$

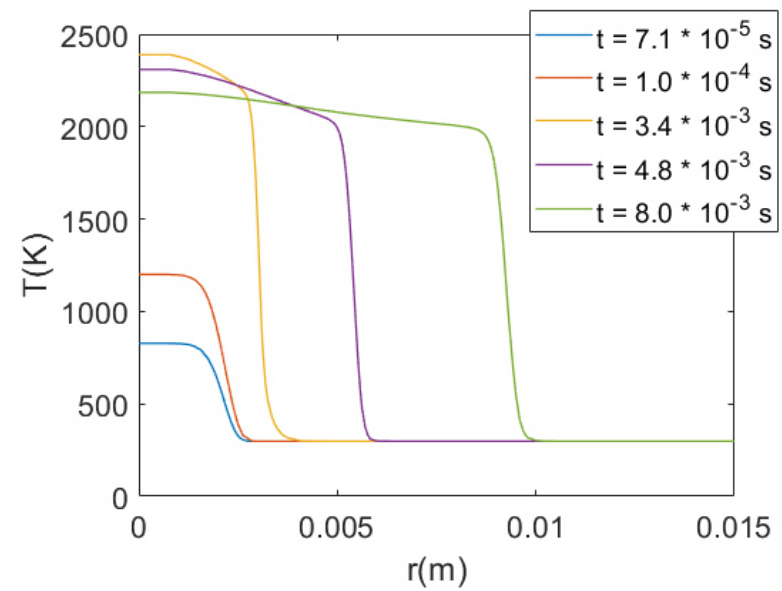

(a) The temperature history for the case of a successful ignition. (Isooctanelair mixture, $\Phi=1.60$, spherical geometry, $r_{s}=2 \mathrm{~mm}$, $q=5.74 \times 10^{5} \mathrm{~J} / \mathrm{m}^{3}$ )

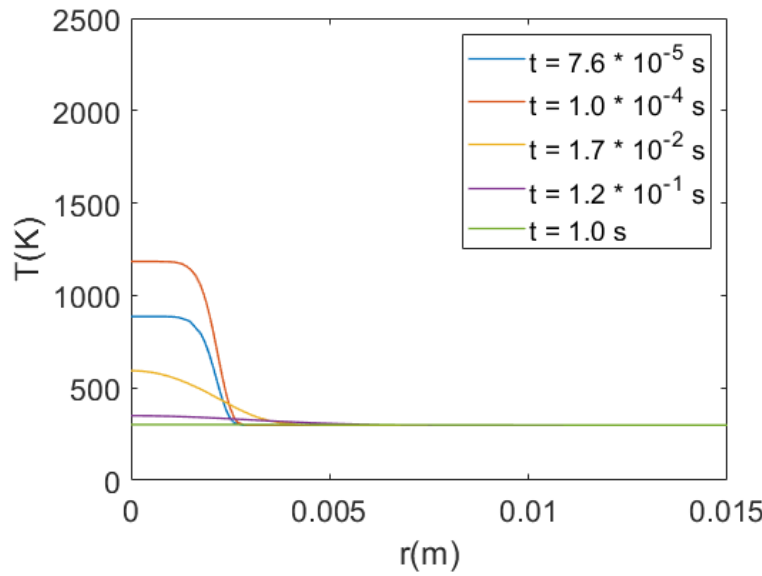

(b) The temperature history of an ignition failure. (Isooctanelair mixture, $\Phi=1.60$, spherical geometry, $r_{s}=2 \mathrm{~mm}, q=5.77 \times 10^{5}$ $\mathrm{J} / \mathrm{m}^{3}$ )

Fig.1 The temperature history of a successful ignition and an ignition failure

\section{Results and discussion}

\subsection{Minimum ignition energies for methane/air mixtures and isooctane/air mixtures}

Fig. 2 shows the results of minimum ignition energies in dependence on the equivalence ratio $\phi$, with spherical ignition source for both fuels. In the diagrams, a normalized equivalence ratio $\phi_{n}$ was used, which allows showing the rich $\left(\phi>1, \phi_{n}>.5\right)$ and lean $\left(\phi<1, \phi_{n}<.5\right)$ side of the flammable range in a nearly symmetric fashion (Law, 2010):

$$
\phi_{n}=\frac{\phi}{1+\phi} .
$$



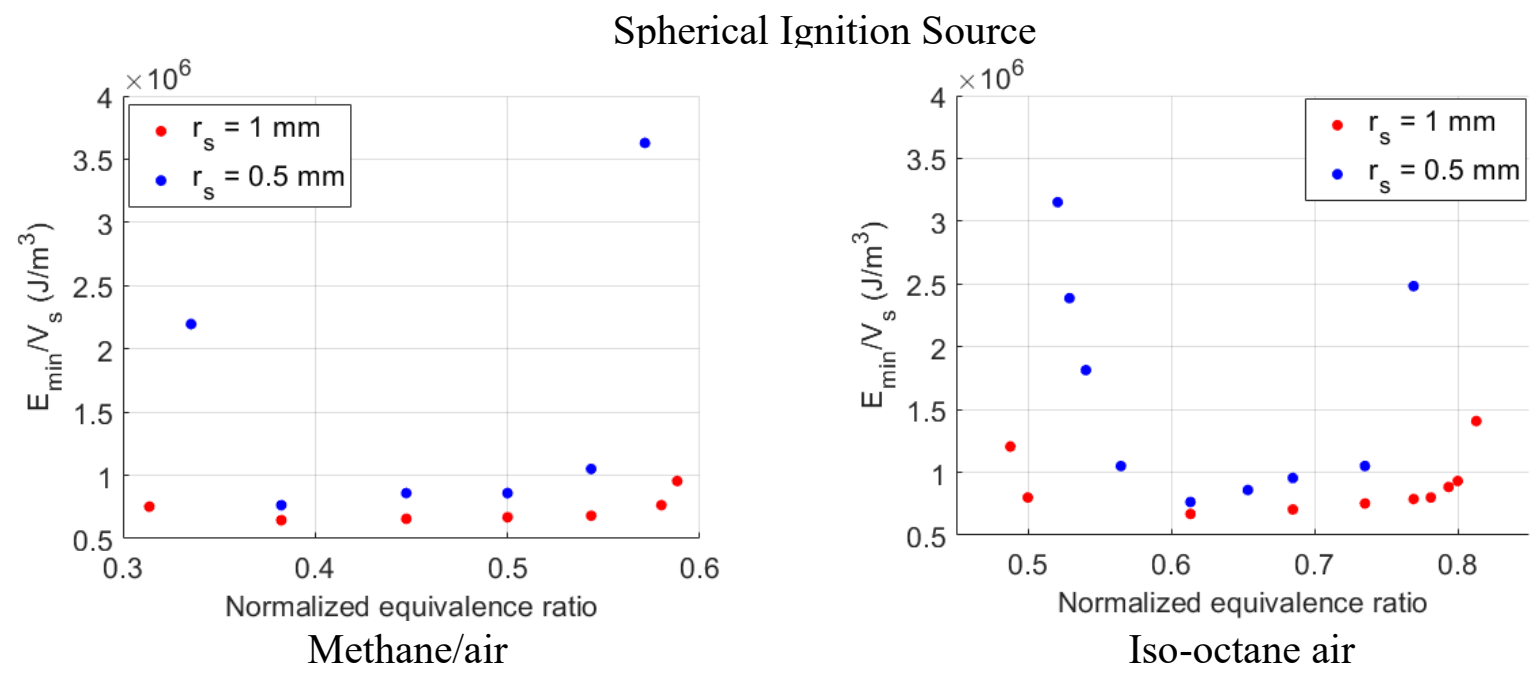

Fig. 2. Minimum ignition energy densities in dependence on the equivalence ratio with a spherical ignition source for two ignition radii $\left(r_{s}=0.5 \mathrm{~mm}\right.$ and $\left.r_{s}=1 \mathrm{~mm}\right)$ for methane/air and isooctane/air mixtures.

Within the flammability limits, the minimum ignition energy densities are comparable for both mixtures. This agrees with the results from Moorhouse (1974). For both mixtures, with a relatively large spherical ignition source $\left(r_{s}=1 \mathrm{~mm}\right)$, the minimum ignition energy density is almost constant within the flammability limits. It increases rapidly near the upper and lower flammability limits. This "U-shape" ignition energy density agrees with former studies (see e.g. Moorhouse et al., 1974). For both fuels, the ignition energy densities for smaller ignition radii $r_{s}$ are higher than for large $r_{s}$. For smaller radii, we observe a notable dependence of MIE on the equivalence ratio also within the flammable range; compare the essentially "flat" curve described by the red points $\left(r_{S}=1 \mathrm{~mm}\right)$ in Fig. 2 with the more variable dependence outlined by the blue points $\left(r_{S}=0.5 \mathrm{~mm}\right)$.

For isooctane/air mixtures, the MIE increases slightly with increasing equivalence ratio from $\phi_{n}=$ 0.62 to $\phi_{n}=0.8(\phi=1.60$ to $\phi=4)$, after that, the MIE increases faster when it approaches the upper flammability limit. On the other hand, at the lean side, the MIE starts to increase from $\phi_{n}=0.6(\phi=$ 1.5). Here the effective Lewis number is above unity, and the Lewis number increases when the equivalence ratio decreases, which makes the minimum ignition energy density especially sensitive to the equivalence ratio. The spherical flame is positively stretched by the outward propagation, the heavy molecules will diffuse to the region with lower temperature. Thus the flame is weakened and perhaps eventually quenches by the stretch effect (Law, 2010, Xin et al., 2012, Han et al., 2015). It is also observed that stoichiometric isooctane/air mixtures with a small spherical ignition source cannot be ignited no matter how large the ignition energy is. This phenomenon will be further discussed in section 3.2.

The results of the minimum ignition energy densities in dependence on the equivalence ratio with a cylindrical ignition source, shown in fig. 3 , are similar to the case of spherical ignition: the minimum ignition energy density is nearly independent of the equivalence ratio within the flammability limits and increases near the limits. The minimum ignition energy densities are higher for smaller ignition radius. Some differences are observed, though. The increase of minimum ignition energy at the flammability limit is lower with cylindrical geometry than with the spherical geometry. The rapidly increasing minimum ignition energy for lean isooctane/air mixture is less pronounced for the cylindrical geometry. This can be attributed to the effect of strongly different diffusivities of the fuel 
and oxidizer, like it is present for iso-octane/air mixtures, in conjunction with different stretch rates for spherical and cylindrical flames.

\section{Cylindrical Ignition Source}
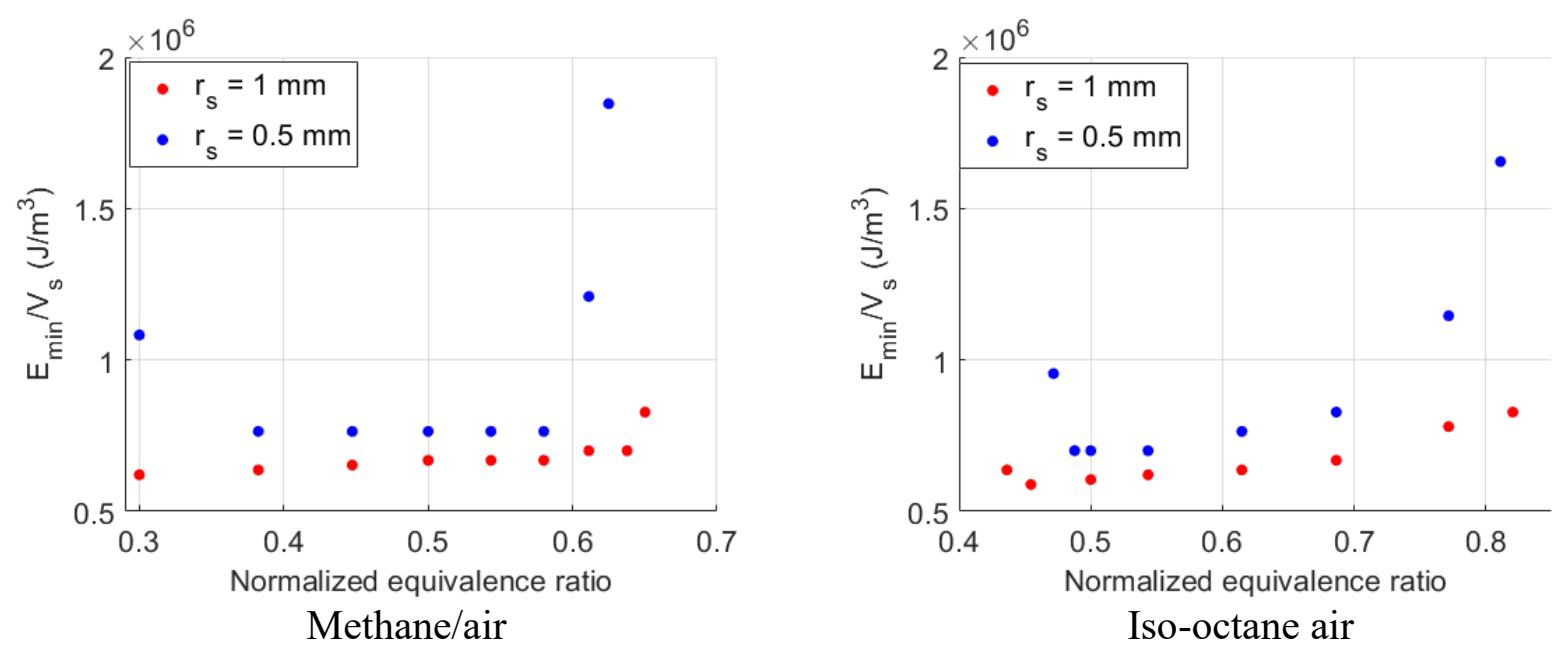

Fig. 3. Minimum ignition energy densities in dependence on the equivalence ratio with a cylindrical ignition source for two ignition radii $\left(r_{s}=0.5 \mathrm{~mm}\right.$ and $\left.r_{s}=1 \mathrm{~mm}\right)$ for methane/air and isooctane/air mixtures.

The stretch rate is defined as the ratio of the time derivation of the area of an infinitesimal element of the flame surface to the area itself. For outwardly propagating spherical flames (spherical flames that propagate in direction of larger radii), the stretch rate is

$$
\kappa=\frac{2}{R_{f}} \frac{d R_{f}}{d t}
$$

and for outwardly propagating cylindrical flames, it is

$$
\kappa=\frac{1}{R_{f}} \frac{d R_{f}}{d t}
$$

where $R_{f}$ is the flame radius (Law, 2010). This indicates a smaller stretch rate for cylindrical flames than for spherical flames, and thus a less pronounced influence of flame front curvature.

\subsection{The curvature effect on minimum ignition energy for isooctane/air mixture}

To further understand the rapid increase of minimum ignition energy density for isooctane/air mixtures from $\phi=1.5\left(\phi_{n}=0.6\right)$ to lean mixtures with spherical geometry, the profiles of $\mathrm{CO}_{2}$ and $\mathrm{CHO}$ are investigated. The values of $\mathrm{CHO}\left(\mathrm{CO}_{2}\right)$ in Fig.4 are given as specific mole numbers, i.e., as the ratio of mass fraction $w_{\mathrm{i}}$ and molar mass $M_{\mathrm{i}}$ of the species:

$$
Y_{i}=\frac{w_{i}}{M_{i}}, \quad i=\mathrm{CHO}, \mathrm{CO}_{2} .
$$

The profiles of $\mathrm{CO}_{2}$ are used to assess to which extent the gas mixture in the ignition volume is already burned; $\mathrm{CO}_{2}$ is thus used as a kind of reaction progress indicator. Note that the temperature, which in other situations can serve as a reaction progress marker, is unsuitable for the purpose here because it 
is affected not only by reaction, but also by the external energy source. The profiles of CHO are used as representatives for the heat release rate. Large values of $\mathrm{CHO}$ indicate regions of large chemical reaction rates, thereby outlining the approximate position of the flame front (Paul et al., 1998).

Stoichiometric Isooctane/Air Mixture with Larger Spherical Ignition Source
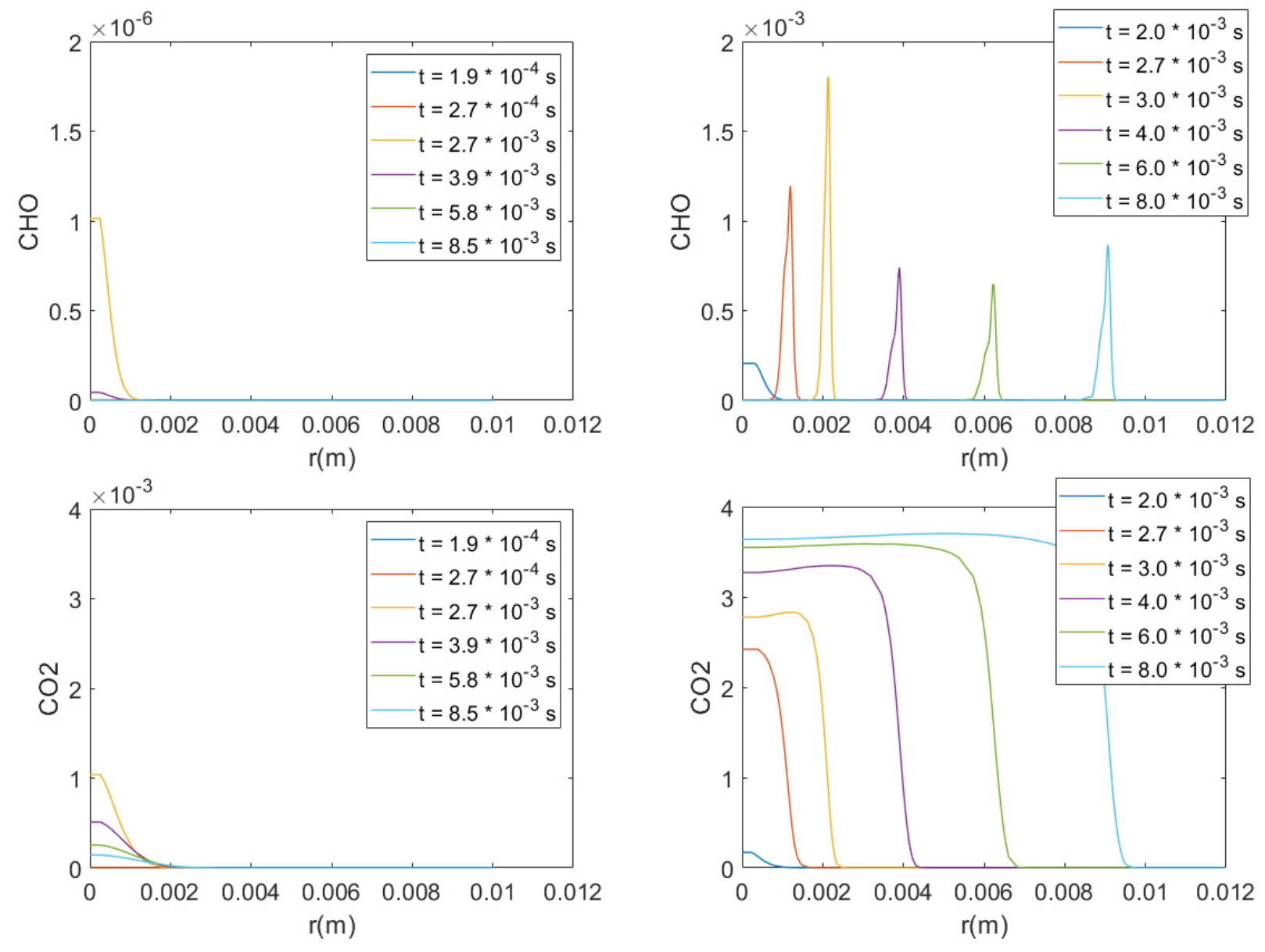

$q=5.37 \times 10^{5} \mathrm{~J} / \mathrm{m}^{3}, E=18.00 \mathrm{~mJ}$

$q=5.39 \times 10^{5} \mathrm{~J} / \mathrm{m}^{3}, E=18.05 \mathrm{~mJ}$

Fig. 4. $\mathrm{CHO}$ and $\mathrm{CO}_{2}$ profiles for stoichiometric isooctane/air mixture with spherical ignition source $\left(r_{s}=2 \mathrm{~mm}\right)$, with no successful ignition (left) and successful ignition (right). Note the different scales on the y-axis for both $\mathrm{CO}_{2}$ and $\mathrm{CHO}$ on the left vs. right side.

For the mixture shown in Fig. 4, the minimum ignition energy density is $q=5.39 \times 10^{5} \mathrm{~J} / \mathrm{m}^{3}$. It is clearly seen that with an ignition energy density $q=5.37 \times 10^{5} \mathrm{~J} / \mathrm{m}^{3}$ only a very limited amount of $\mathrm{CO}_{2}$ is formed (about $10^{-3}$, which means the mass fraction of $\mathrm{CO}_{2}$ is about $0.0044 \%$ ), which means the energy is not enough to ignite the mixture in the ignition volume. However, with $q=5.39 \times 10^{5} \mathrm{~J} / \mathrm{m}^{3}$, we can see the formation of $\mathrm{CO}_{2}$ and the propagation of the flame.

On the other hand, the stoichiometric isooctane/air mixture with an ignition source $r_{s}=1 \mathrm{~mm}$ behaves differently, as is shown in Fig.5. 
Stoichiometric Isooctane/Air Mixture with Smaller Spherical Ignition Source
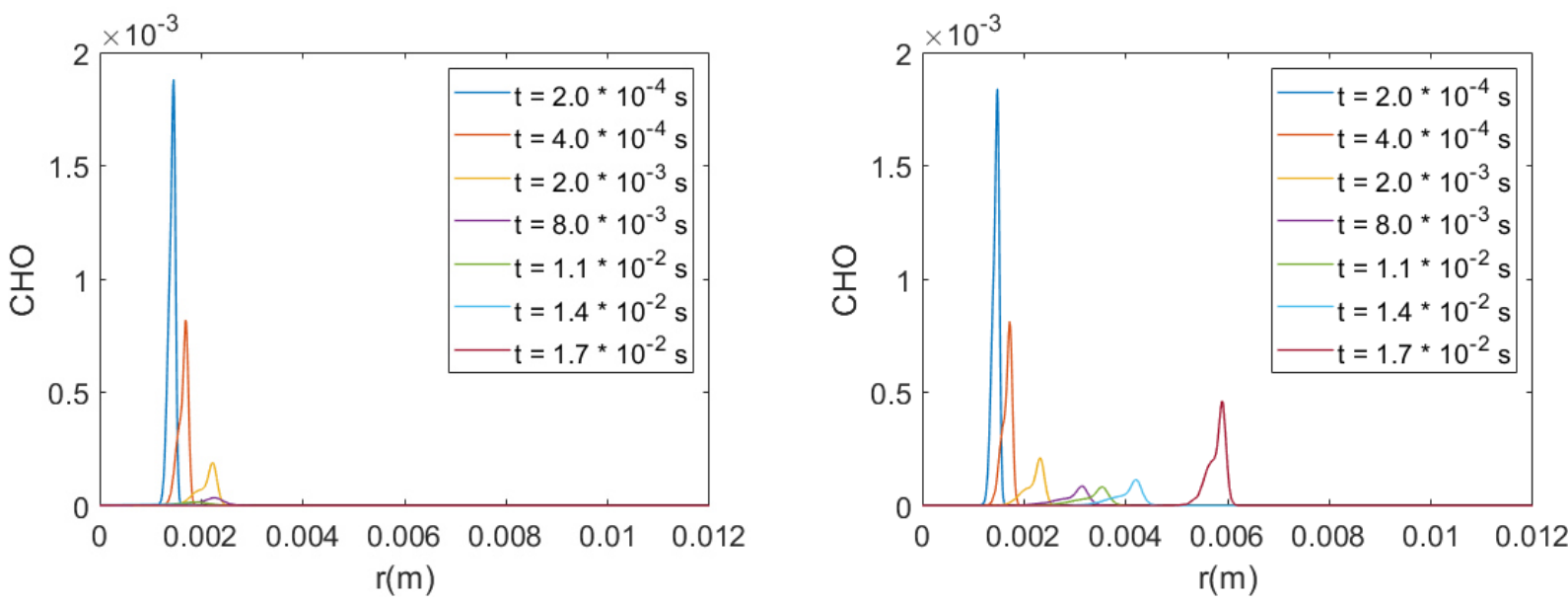

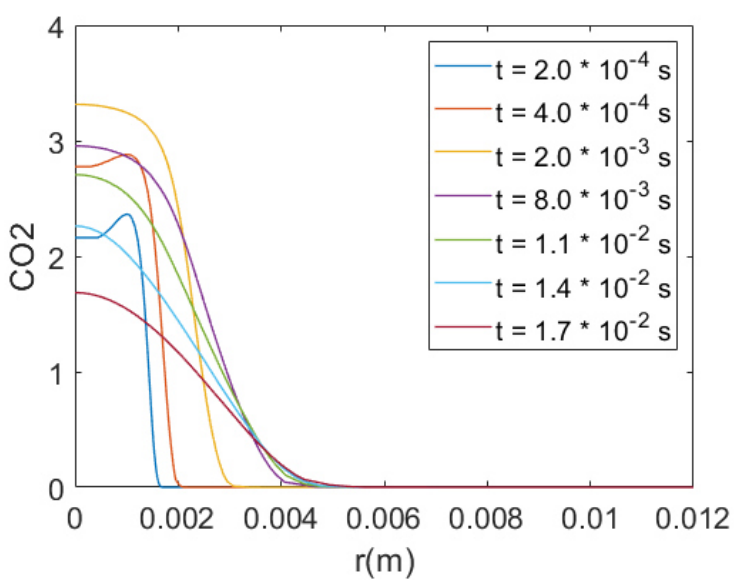

(a)

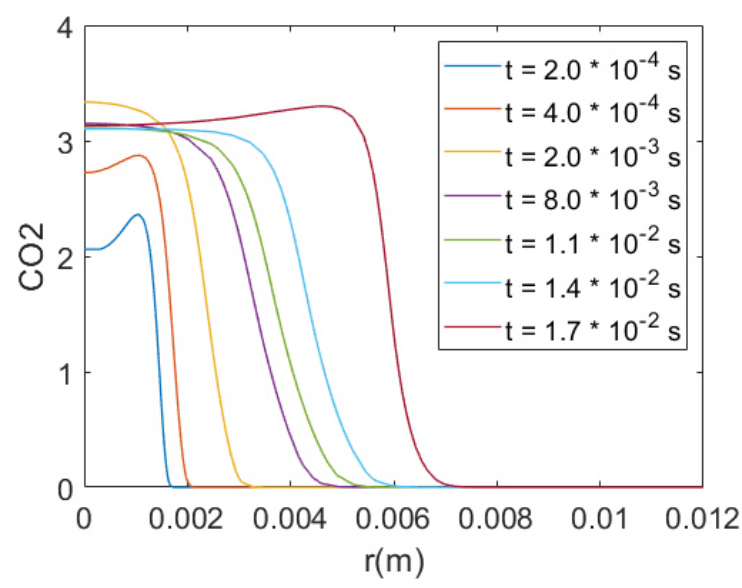

(b)

Fig. 5. The $\mathrm{CHO}$ and $\mathrm{CO}_{2}$ profiles for stoichiometric isooctane/air mixture with spherical ignition source $\left(\boldsymbol{r}_{\boldsymbol{s}}=1 \mathrm{~mm}\right)$ with source energy of: (a) $q=7.88 \times 10^{5} \mathrm{~J} / \mathrm{m}^{3}(E=3.25 \mathrm{~mJ})$, no flame propagation and $(b) q=8.00 \times 10^{5} \mathrm{~J} / \mathrm{m}^{3}(E=3.35 \mathrm{~mJ})$, flame propagation

Here the minimum ignition energy density is $8.00 \times 10^{5} \mathrm{~J} / \mathrm{m}^{3}$. In contrast to the results of $r_{s}=2 \mathrm{~mm}$, where no ignition was found below the minimum ignition energy, here, even when the source energy density is $7.88 \times 10^{5} \mathrm{~J} / \mathrm{m}^{3}$ (below the MIE), the mixture in the ignition volume is still ignited. During the first $2 \mathrm{~ms}$, the $\mathrm{CO}_{2}$ formation and the propagation of the peak of $\mathrm{CHO}$ are very similar. But when the reaction front (as identified by the peak of $\mathrm{CHO}$ ) has moved about $2 \mathrm{~mm}$ away from the ignition source, the flame quenches. The ignition energy density $q=7.88 \times 10^{5} \mathrm{~J} / \mathrm{m}^{3}$ is therefore enough to generate a flame kernel, but the flame cannot further propagate.

We define the distance between the $\mathrm{CHO}$ peak and the left boundary of the calculation domain $(r=$ 0 ) as the flame radius. The evolution of this for the different cases is shown in fig. 6 . The propagation and extinction of the flame is clearly seen in Fig. 6. For the ignition source radius $r_{\mathrm{s}}=2 \mathrm{~mm}$, when the ignition energy density increases, the temperature in the center also increases, when there's enough energy for the ignition of the mixture in the ignition volume, the flame is formed and can propagate. On the other hand, for the ignition source radius $r_{\mathrm{s}}=1 \mathrm{~mm}$, even if the mixture in the ignition volume can be ignited and a flame is formed, the flame will quench if the ignition energy is not high enough. 


$$
\mathrm{r}=2 \mathrm{~mm}
$$
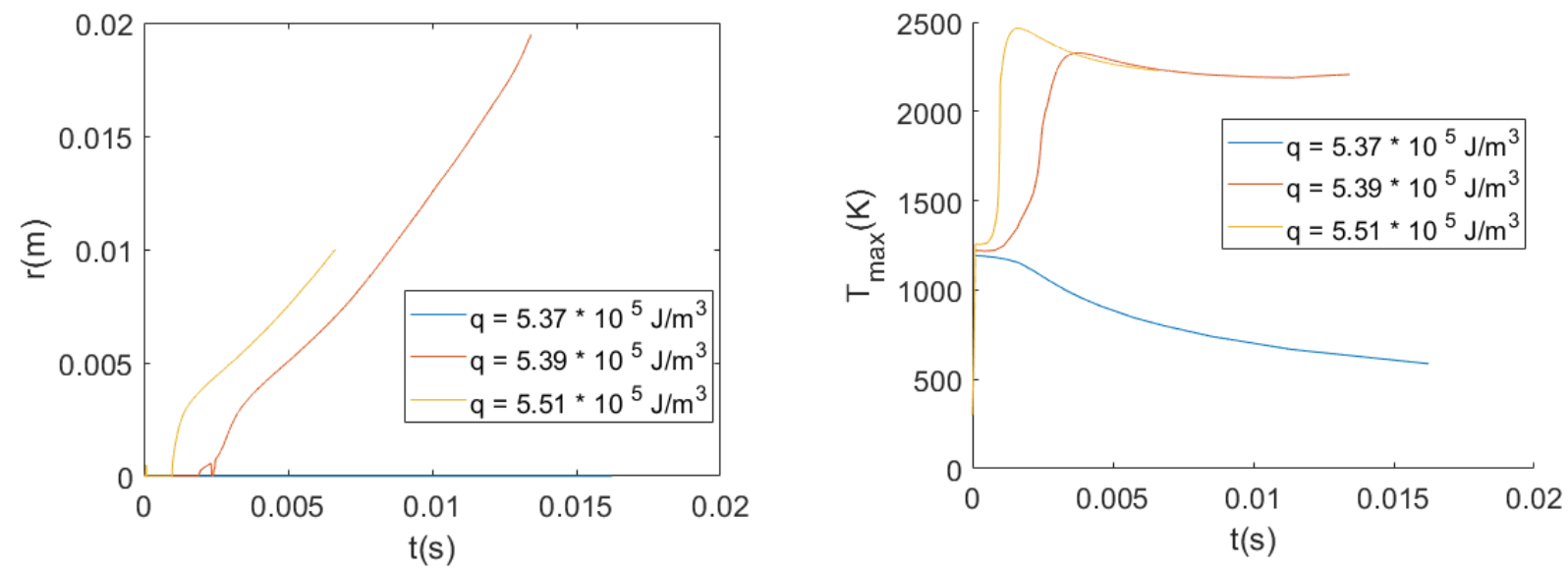

$$
\mathrm{r}=1 \mathrm{~mm}
$$

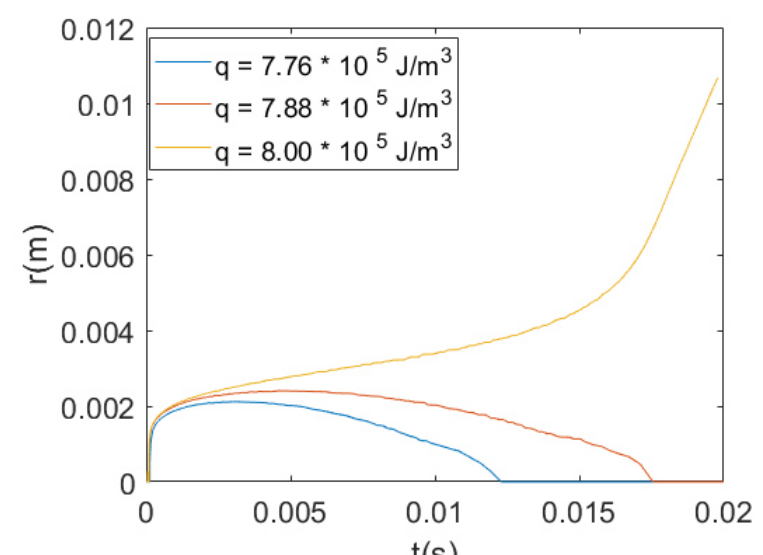

$\mathrm{t}(\mathrm{s})$

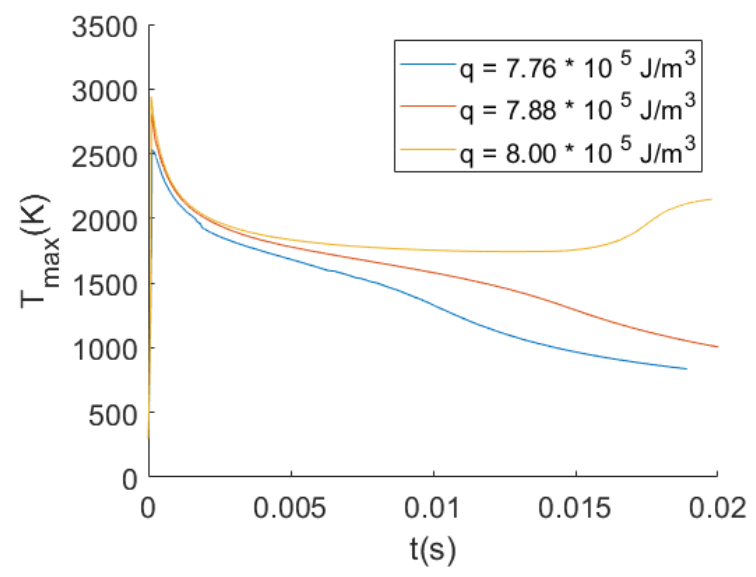

$\mathrm{r}=0.5 \mathrm{~mm}$
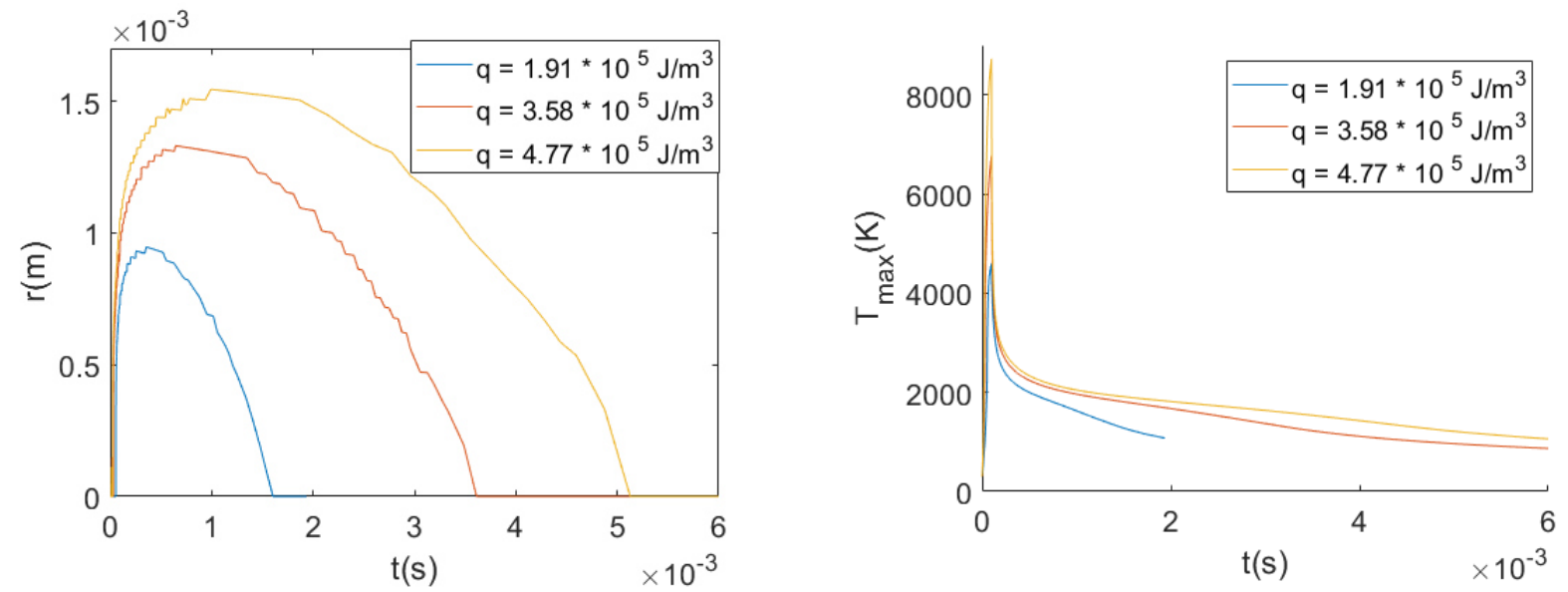

Fig. 6. Temporal development of the flame radius and of the maximal temperature for stoichiometric isooctane/air mixtures with a spherical source $r_{s}=2 \mathrm{~mm}$ (top) $r_{s}=1 \mathrm{~mm}$ (middle) and $r_{s}=0.5 \mathrm{~mm}$ (bottom). 
According to He (2000) and Kelley et al. (2008), a critical flame radius exists. For a positively stretched spherical flame, if the flame can reach this critical radius, then the flame can further propagate. Otherwise the flame quenches. Hence for smaller ignition radii, more energy is needed to reach the critical radius.

In Fig.6, we can clearly see this critical radius (about $0.0025 \mathrm{~m}$ ) for smaller ignition sources. For $r_{\mathrm{s}}=1 \mathrm{~mm}$, if the ignition energy density $\mathrm{q}$ is $7.88 \times 10^{5} \mathrm{~J} / \mathrm{m}^{3}$, the flame will propagate to a radius about $2.2 \mathrm{~mm}$, which is smaller than the critical radius, and then quenches. If the ignition energy density q is even smaller than $7.88 \times 10^{5} \mathrm{~J} / \mathrm{m}^{3}$, the flame quenches at even smaller radii. On the other hand, if the ignition energy density is a little bit higher and reach the minimum ignition energy density, the flame can reach the critical radius and further propagate.

This can also explain why the stoichiometric isooctane/air mixture cannot be ignited with a spherical source $r_{s}=0.5 \mathrm{~mm}$. As is shown in Fig.6, the temperature in the center increases up to $8000 \mathrm{~K}$, and the initiated flame still cannot reach the critical flame radius for stoichiometric isooctane/air mixture. As a result, the flame quenches and the rest of the mixture remains unignited.

\subsection{The dependence of minimum ignition energies on the ignition radius for isooctane/air} mixtures

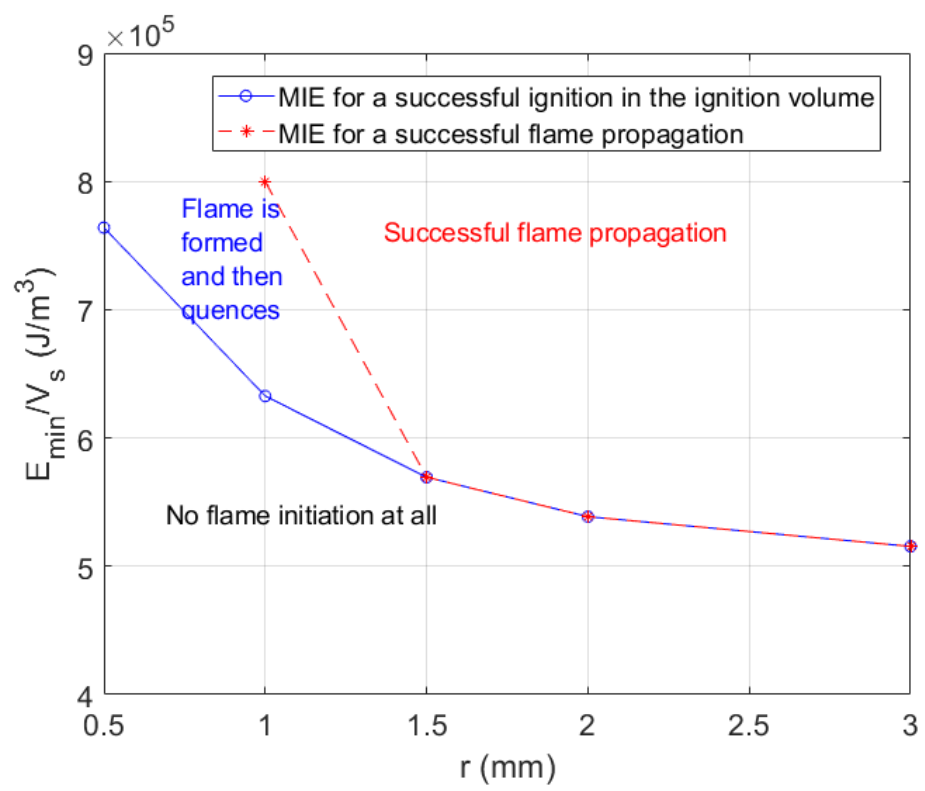

Fig. 8. The dependence of minimum ignition energy on ignition radius for stoichiometric isooctane/air mixture with spherical ignition source

Fig. 8 shows the dependence of minimum ignition energy densities on the ignition radius for stoichiometric isooctane/air mixtures with spherical ignition sources. As discussed in section 3.2, for mixtures like stoichiometric isooctane/air with Le $>1$, the flame kernel must reach a certain radius for a successful flame propagation (He, 1999, Kelley et al. 2008). Results show that if $r_{s}>1.5 \mathrm{~mm}$, the minimum ignition energy densities for the flame initiation in the ignition volume and for a successful flame propagation are the same, and it decreases slightly when the ignition radius increases due to heat conduction becoming less important. This means that either the mixture can be ignited and the flame can propagate, or the energy is not enough to ignite the mixture at all. However, as $r_{s}<1.5 \mathrm{~mm}$, a third region becomes more significant, where the energy is enough to ignite the mixture ignition 
kernel, but not enough for the flame to propagate to the critical radius. The flame quenches because of the curvature effect at small flame radius.

\section{Conclusions}

In this study, the dependence of the minimum ignition energies (MIEs) on the fuel composition, the ignition source geometry and the ignition source size for methane/air mixtures and isooctane/air mixtures is investigated.

The MIE vs. equivalence ratio diagrams for both fuels show "U"-shaped curves. Within the flammability limits, the MIE stays almost constant, and it increases rapidly at the limits. The MIEs for both fuels are also similar within the flammability limits.

However, for isooctane/air mixture with $\Phi<1.5$, where the Lewis number is above 1 and further increases when the mixture gets leaner, the MIE is very sensitive to the change of equivalence ratio. For $r_{s}=0.5 \mathrm{~mm}$, even a stoichiometric mixture of isooctane/air cannot be ignited. The main reason for this is related to the curvature of the reaction zone: For small flame radii and the resulting large stretch rates, molecular diffusion has a strong effect on the evolution of the system. Strong gradients at the reaction zone cause large fluxes of species. The isooctane molecule cannot diffuse into the reaction zone at the same rate like oxygen; this leads to a local lack of fuel at the reaction zone, which in turn reduces the chemical source terms. This impedes a sufficiently fast propagation. This phenomenon is less pronounced for a cylindrical ignition kernel, because the stretch rate for a cylindrical flame is smaller and thus the curvature effect is smaller as in the spherical case.

In contrast, for methane/air mixtures, even with small ignition radii this phenomenon mentioned above is not observed: if the energy is large enough for an ignition in the center, then the flame is also able to propagate. The curvature effect for methane/air mixture is negligible.

Furthermore, we investigated the flame front propagation for spherical isooctane/air flames. Results show that for larger ignition sources, the mixture can either be ignited in the center and the flame is able to propagate, or the mixture cannot be ignited at all. On the other hand, with a smaller ignition source, it is possible that a flame is formed but then quenches.

For $r_{s}>1.5 \mathrm{~mm}$, the minimum ignition energy densities for a flame initiation in the ignition volume and for a successful flame propagation are the same. Bur for $r_{s}<1.5 \mathrm{~mm}$, there's a difference between the two minimum ignition energy densities. The difference becomes larger for smaller ignition radii.

\section{Acknowledgements}

The authors gratefully acknowledge the financial contribution from the Deutsche Forschungsgemeinschaft (DFG) under the project MA1205/26-1.

\section{References}

Abdel-Gayed, R.G., Bradley, D., Hamid, M.N., Lawes, M. (1985). Lewis number effects on turbulent burning velocity, Symposium (International) on Combustion, 20(1): 505-512

Andrae, J.C.G., Brinck, T., \& Kalghatgi, G.T. (2008). HCCI experiments with toluene reference fuels modeld by a semidetailed chemical kinetic model. Combustion and Flame, 155(4): 696-712

Chen, Z. \& Ju, Y. (2007) Theoretical analysis of the evolution from ignition kernel to flame ball and planar flame, Combustion Theory and Modelling, 11:3, 427-453.

Clarke, A. (2002). Calculation and Consideration of the Lewis Number for Explosion Studies. Process Safety and Environmental Protection. 80(3): 135-140 
Frendi, A. \& Sibulkin, M. (1990). Dependence of minimum ignition energy on ignition parameters. Combustion Science and Technology. 73: 395-413.

Han, W. \& Chen, Z. (2015). Effects of Soret diffusion on spherical flame initiation and propagation. International Journal of Heat and Mass Transfer. 82: 309-315

He, L. (2000) Critical conditions for spherical flame initiation in mixtures with high Lewis numbers. Combustion Theory and Modelling. 4(2): 159-172

He, L. \& Law, C.K.(1999). On the Dynamics of Transition from Propagating Flame to Stationary Flame Ball. AlAA 99-0325.

Kelley, A.P., Jommas, G. \& Law, C.K. (2008). Critical radius for sustained propagation of spark ignited spherical flames. Combustion and Flame. 156(5): 1006-1013

Law, C.K. (2010). Combustion physics. Cambridge University Press.

Lewis, B., Von Elbe, G. (1987). Combustion, Flames and Explosions of Gases, Third Edition. Academic Press

Maas, U. \& Warnatz, J. (1988). Ignition processes in hydrogen-oxygen mixtures, Combustion and Flame, 74(1): 53-69.

Mills, I., Cvitas, T., Homann, K., Kallay, N., Kuchitsu, K., Quantities (1993), Units and Symbols in Physical Chemistry. Second Edition. Blackwell Schience.

Moorhouse, J., Williams, A. \& Maddison, T.E. (1974). An investigation of the minimum ignition energies of some C1 to C7 hydrocarbons, Combustion and Flame, 23(2): 203-213

Paul, P.H. \& Najm, H.N. (1998), Planar laser-induced fluorescence imaging of flame heat release rate, Symposium (International) on Combustion. 27(1):43-50

Takashi, H. \& Kimitoshi, T. (2006). Lamina flame speeds of ethanol, n-heptane, isooctane air mixtures.

Smith, G.P., Golden, D.M., Frenklach, M., Moriarty, N.W., Eiteneer, B., Goldenberg, M., Bowman, C.T., Hanson, R.K., Song, S., Gardiner, W.C., Jr., Lissianski, V.V., \& Qin, Z. (2004) GRI-MECH $3.0 \mathrm{http}: / /$ www.me.berkeley.edu/gri_mech/

Warnatz, J., Maas, U. \& Dibble, R.W. (2006), Combustion - Physical and chemical fundamentals, modeling and simulation, experiments, pollutant formation. Fourth edition. Springer.

Williams, F. A. (1975). Recent advances in theoretical descriptions of turbulent diffusion flames. In Turbulent mixing in nonreactive and reactive flows. Springer.

Xin, Y., Sung, C. \& Law, C.K. (2012). A mechanistic evaluation of Soret diffusion in heptane/air flames. Combustion and Flame. 159(7): 2345-2351 